\title{
HORMONE
}

RESEARCH

Aimaretti, G. 26

Albertsson-Wikland, K. 17

Baldelli, R. 26

Bang, P. 50

Berg, U. 50

Buckway, C. 37

Christensen, J.J. 73

Christiansen, J.S. 73

Clark, R.G. 93

Clayton, P.E. 2

Clemmons, D.R. 77

Cohen, P. 59

Corneli, G. 26
Darendelliler, F. 17

Dunger, D.B. 101

Fisker, S. 73

Ghigo, E. 26

Gibney, J. 66

Gleeson, H. 44

Granata, R. 26

Grottoli, S. 26

Guevara-Aguirre, J. 37

Hall, C.M. 2

Holzenberger, M. 89

Jenkins, P.J. 108

Johannsson, G. 66
Jørgensen, J.O.L. 73

Krag, M. 73

Landin-Wilhelmsen, K. 8

Lappas, G. 8

Lindberg, A. 17

Lissett, C.A. 44

Lundberg, P.-A. 8

Ong, K. 101

Ovesen, P. 73

Paisley, A.N. 83

Park, P. 59

Pratt, K.L. 37

Price, D.A. 17
Ranke, M.B. 17

Reiter, E.O. 17

Rosenfeld, R.G. 37

Rovere, S. 26

Schweizer, R. 17

Selva, K. 37

Shalet, S.M. 44

Thorner, M.O. 34

Trainer, P.J. 83

Wilhelmsen, L. 8

Yuen, K. 101

\section{Subject Index Vol. 62, Suppl. 1, 2004}

Acid-labile subunit 44

Acromegaly 34, 83, 108

Adolescents 17

Adults 8, 26, 34, 44, 66, 73, 77, 83

Ageing 89

Breast cancer 108

Children 2, 17, 37, 59

Colorectal cancer 108

Diabetes mellitus 77

Exercise, single or repeated bouts 50

Gene polymorphisms 77

GH/IGF-I axis 108

Glucose metabolism 77

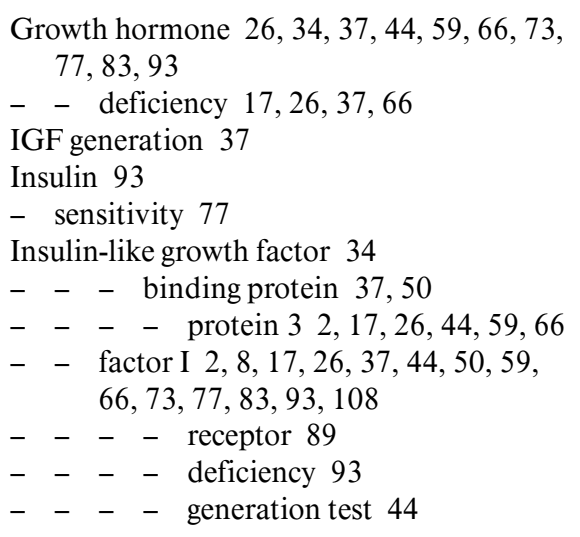

KIGS 17

KIMS 83

Mice resistant to oxidative stress 89

Muscle concentration after training 50

Optimization of dosing 59

Oxidative stress 89

Primary insulin-like growth factor I deficiency 93

Prostate cancer 108

Puberty 17

Sex steroids 73

Signalling pathway inactivation 89

\section{KARGER ( 2004 S. Karger AG, Basel}

